\title{
Life Cycle Assessment of Urban Food Consumption
}

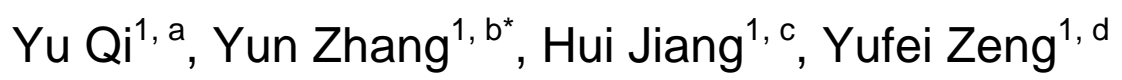 \\ ${ }^{1}$ Key Laboratory of Industrial Ecology and Environmental Engineering (MOE), \\ School of Environmental Science and Technology, Dalian University of Technology, \\ Linggong Road 2, Dalian 116024, China \\ a qiyudlut@126.com, bzhangyun@dlut.edu.cn, '610020636@qq.com, dzengyufei@163.com \\ ${ }^{*}$ Correspondence to: Yun Zhang; Tel.: +86 411 84706151; E-mail address: zhangyun@dlut.edu.cn
}

Keywords: life cycle assessment (LCA); urban food consumption; environmental impacts Abstract. Rapid urbanization brings a quick growth of urban environmental pressure. Food consumption is taken as one of the most resource demanding and polluting daily activities in urban life, and is also the important part of urban environmental impact. We calculated the environmental impact of urban food consumption of a Chinese city named Dalian in 2012, including human ingestion and human excretion. The results show the degree of contributions made by all stages of food consumption to impact categories, and that food production and home cooking are the main contributors of environmental impact of Dalian in 2012. Decision-makers can optimize the corresponding stages of urban food consumption for different environmental problems, and the results can provide technical support for urban environmental impact assessment.

\section{Introduction}

With rapid urbanization, urban residents are playing increasingly important roles in environmental impacts. Food is the most important consumable of daily household life, which has brought a pressure to environment. The greenhouse gases caused by food production, distribution and consumption in England account for $20 \%$ of the total environmental impact. The energy consumption related to food in Sweden and America account for $12 \%$ and $10 \%$ of household energy consumption, respectively [1, 2]. As a big agricultural country, the food consumption of China has a great impact on global environment and economy. Life cycle assessment (LCA) has been developed to assess the environmental impacts throughout a product's life cycle [3], and it can identify the degree of contribution to the environment made by each stage of food consumption, like food production, home cooking and human excretion. We calculated the environmental impact of urban food consumption of a Chinese city named Dalian in 2012, including human ingestion and human excretion. We quantified the environmental impact of each stage and provide a technical support for environmental impact assessment on urban territory.

When use a life cycle perspective, food consumption is taken as one of the most resource demanding and polluting daily activities [4]. Several international studies have identified urban food consumption as one of the main contributors to the environmental impacts. [5] Roy et al. used a network of information sharing and exchange of experience which had expedited the LCA development process. [6] Muñoz et al. developed a simple model to evaluate environmental impact of food product including consumption of energy and materials related to toilet use. [7] We adapted this method to evaluate urban food consumption, which could provide a basis for environmental impact assessment on urban territory.

\section{Methodology}

According to internationally recognized ISO 14000 environmental management standards, the four steps of LCA include scope and target determination, inventory analysis, impact assessment and result interpretation. [8] 
A functional unit is a "quantified performance of a product system for use as a reference unit”. [9] In urban food consumption system, per capita or per year level can be the functional unit of the study. We adapted per annual food production of the studied city as the functional unit.

Boundary selection determines the studied units. The units included in this study are food production, transport, home cooking, ingestion, human excretion and waste treatment. These units form the life cycle of food. The system boundary is showed in Fig. 1.

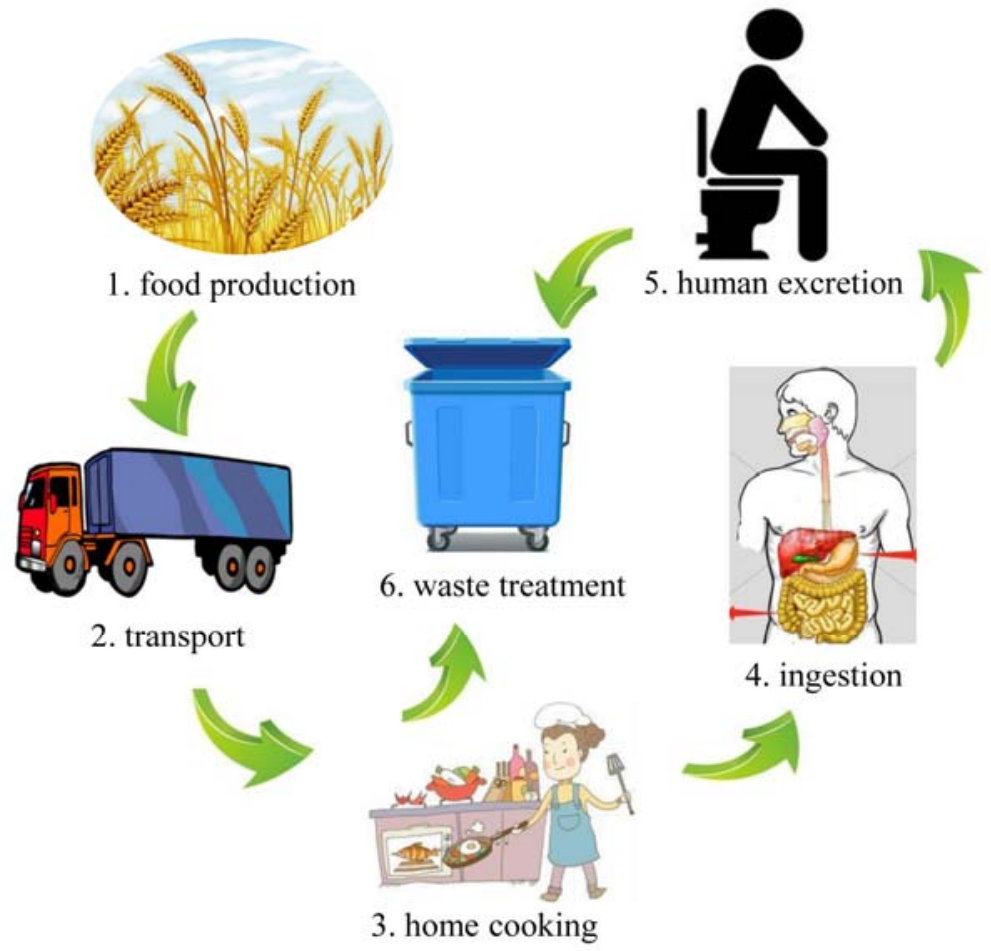

Fig. 1 The system boundary of the study

Data collection and processing are required in inventory analysis. The food yield of Dalian in 2012 is showed in table 1. Due to the lack of data for modeling in China, there are two approaches can be adopted: similar process could be substitute for some kinds of foods; use individual data take place of species data. For example, in the LCA of meat, the data of pork can replace the data of meat.

Table 1 Food yield of Dalian in 2012

\begin{tabular}{llll}
\hline & & Yield $\left[10^{7} \mathrm{~kg}\right]$ & Percentage [\%] \\
\hline Grains & Cereal & 144.18 & 15.46 \\
& Others & 21.38 & 2.29 \\
Vegetables & 257.03 & 27.56 \\
Fruits & 173.8 & 18.63 \\
Meat & 79.72 & 8.55 \\
Eggs & 28.66 & 3.07 \\
Dairy product & 8.36 & 0.90 \\
Aquatic product & 219.55 & 23.54 \\
\hline
\end{tabular}

The product system modeling software $\mathrm{GaBi}$ was utilized to model the food consumption. $\mathrm{GaBi}$ contains many specialized databases used for life cycle assessment, which saves a lot of computing time. The method chosen to assess the impacts is ReCiPe. The impact categories of the study are characterized at the midpoint level from the hierarchist perspective.

Due to the correlation of human excretion and waste treatment, they are merged into one section. 


\section{Results interpretation and discussion}

We transformed the inventory data into 12 impact categories. The 12 impact categories are showed in table 2.

Table 2 Impact categories at the midpoint level from the hierarchist perspective in ReCiPe

\begin{tabular}{ll}
\hline Impact category & Abbreviation \\
\hline Climate change & CC \\
Freshwater ecotoxicity & FET \\
Freshwater eutrophication & FE \\
Human toxicity & HT \\
Ionising radiation & IR \\
Marine ecotoxicity & MET \\
Marine eutrophication & ME \\
Ozone depletion & OD \\
Particulate matter formation & PMF \\
Photochemical oxidant formation & POF \\
Terrestrial acidification & TA \\
Terrestrial ecotoxicity & TET \\
\hline
\end{tabular}

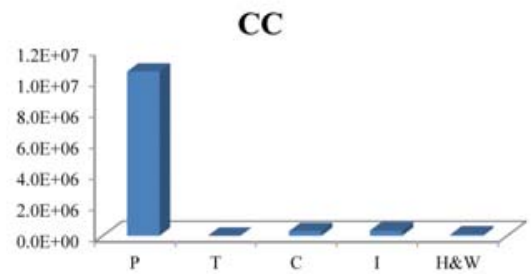

HT

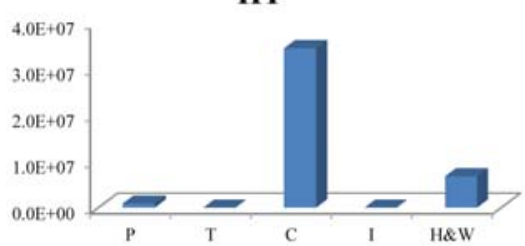

ME

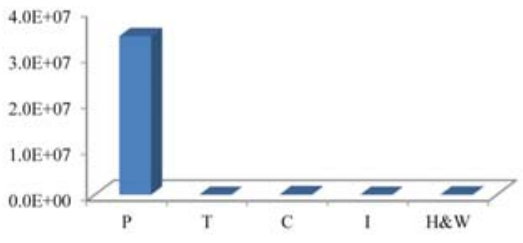

POF

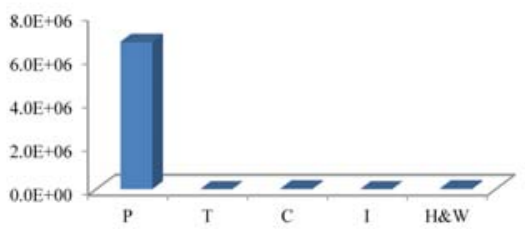

FET

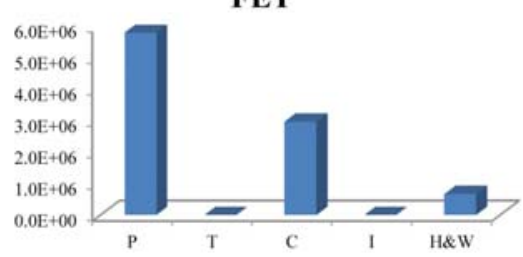

IR

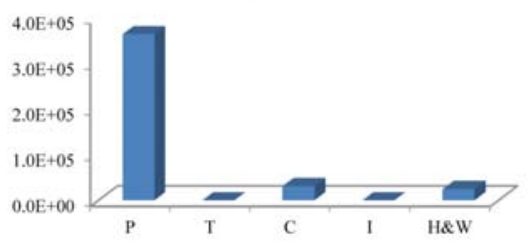

OD

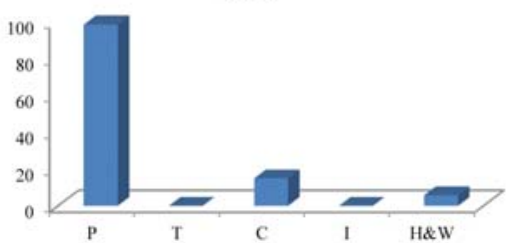

TA

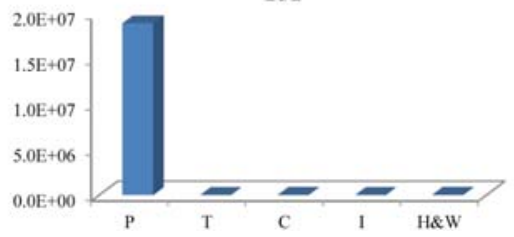

FE

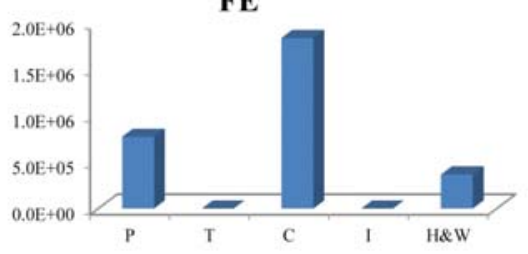

MET

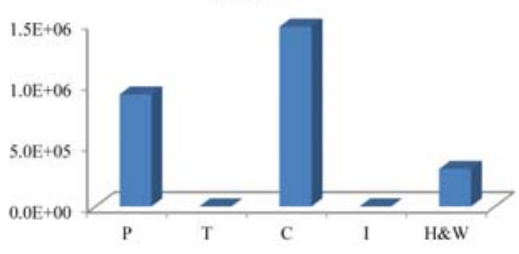

PMF

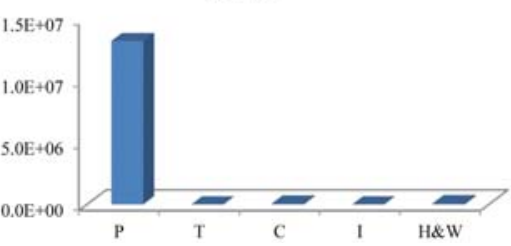

TET

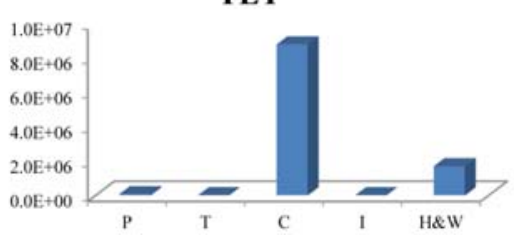

Fig. 2 Environmental impact of 12 impact categories of Dalian's food consumption in 2012 ( $\mathrm{P}=$ production, $\mathrm{T}=$ transport, $\mathrm{C}=$ home cooking, $\mathrm{I}=$ human ingestion, $\mathrm{H} \& \mathrm{~W}=$ human excretion \& waste treatment)

Environmental impact of 12 impact categories of Dalian's food consumption in 2012 is showed in Fig. 2. The impact categories CC, FET, IR, ME, OD, PMF, POF and TA are dominated by food production, while FE, HT, MET and TET are dominated by home cooking. Human excretion \& waste 
treatment also makes a contribution to FET, FE, HT, MET and TET. Transport and ingestion have little impact on 12 impact categories, compared with other stages. From the results, we can see the main contributors of kinds of environmental problems. For example, for freshwater ecotoxicity problem, food production makes the most contribution to freshwater ecotoxicity, and accounts for $61.45 \%$. Home cooking and human excretion \& waste treatment account for $31.50 \%$ and $7.04 \%$, respectively. If decision-makers want to decrease the impact of freshwater ecotoxicity, the effort to improve food production and home cooking must be made. For example, government can encourage farmers to reduce the use of pesticide when planting food or encourage residents to reduce food waste when cooking.

\section{Conclusion}

Rapid urbanization brings a quick growth of urban environmental pressure. As the most important consumable of daily household life, food consumption makes a contribution to urban environmental impact. LCA can perform a comprehensive assessment of the product or service, and quantify the impact of each stage to provide accurate technical support. We evaluated the environmental impact of Dalian's food consumption in 2012, including human ingestion and human excretion. The results show that food production (especially aquatic production) and home cooking are the main contributors of environmental impact. Decision-makers can optimize the corresponding stages for different environmental problems. The study could provide a basis for environmental impact assessment on urban territory in China. Due to the complexity of food category, environmental impact assessment of all kinds of food has more challenges.

\section{Acknowledgements}

This study was supported by the Major Science and Technology Program for Water Pollution Control and Treatment (2012ZX07202-001).

\section{References}

[1] H. Payer, P. Burger and S. Lorek: Paper for the OECD Environment Directorate, Pro-gramme on Sustainable Consumption. (2000)

[2] J. Kaufmann, F. Chevrot: Cambridge: Draft Report to the Organization for Economic Co-operation and Development. (2000)

[3] G. Rebitzer, T. Ekvall, R. Frischknecht: Environment International. 30: 701-720. (2004)

[4] I. Muñoz, L.M. i Canals and A.R. Fernández-Alba: The International Journal of Life Cycle Assessment, 15(8): 794-805. (2010)

[5] D.S. Nijdam, H.C. Wilting, M.J. Goedkoop and J. Goedkoop: J Ind Ecol 9(1-2):147-168. (2005)

[6] P. Roy, D. Nei, T. Orikasa et al.: Journal of food engineering, 90(1): 1-10. (2009)

[7] I. Muñoz, L.M. i Canals and A. Rodríguez: Parallel 1a: Life cycle inventory, databases and tools, 61. (2009)

[8] ISO: International Organization for Standardization, Life Cycle Assessment - Requirements and Guidelines, ISO 14040. (2006)

[9] ISO: Environmental management-life cycle assessment-principles and framework. ISO 14040, Geneva. (2006) 